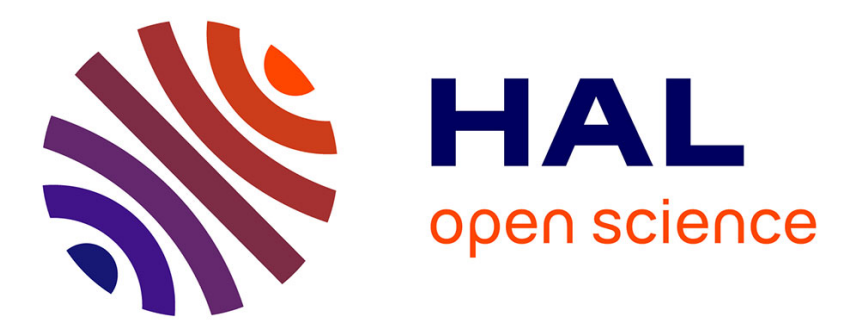

\title{
A study of transverse cracking in laminates by the Thick Level Set approach
}

Thibault Gorris, Paul-Émile Bernard, Laurent Stainier

\section{To cite this version:}

Thibault Gorris, Paul-Émile Bernard, Laurent Stainier. A study of transverse cracking in laminates by the Thick Level Set approach. Mechanics of Materials, 2015, 90, pp.118-130. 10.1016/j.mechmat.2015.05.003 . hal-01150856

\section{HAL Id: hal-01150856 https://hal.science/hal-01150856}

Submitted on 12 May 2015

HAL is a multi-disciplinary open access archive for the deposit and dissemination of scientific research documents, whether they are published or not. The documents may come from teaching and research institutions in France or abroad, or from public or private research centers.
L'archive ouverte pluridisciplinaire HAL, est destinée au dépôt et à la diffusion de documents scientifiques de niveau recherche, publiés ou non, émanant des établissements d'enseignement et de recherche français ou étrangers, des laboratoires publics ou privés. 


\title{
A study of transverse cracking in laminates by the Thick Level Set approach
}

\author{
Thibault Gorris ${ }^{\mathrm{a}}$, Paul-Émile Bernard ${ }^{\mathrm{b}}$, Laurent Stainiera,* \\ ${ }^{a}$ Institut de Recherche en Génie Civil et Mécanique (GeM, UMR 6183 CNRS) \\ École Centrale Nantes, 1 rue de la Noë, BP 92101, F-44321 Nantes, France \\ ${ }^{b}$ Institute of Mechanics, Materials and Civil Engineering (iMMC) \\ Université catholique de Louvain, 4 ave. G. Lemaître, B-1348 Louvain-la-Neuve, Belgium
}

\begin{abstract}
In this paper, we present an analysis of the transverse cracking and interface failure process induced in layered materials (such as composite laminates) subjected to tensile loading, with a new level set based non-local modeling approach for damage growth (TLS: Thick Level Set). In particular, a 2D finite element model is built to study damage in a cross-ply laminate. The study aims at evaluating the capacity of the TLS method to predict evolution of damage at the ply level, including initiation, propagation, merging of cracks or delamination. We show how this numerical model is able to reproduce key features such as crack spacing saturation and other experimental observations.
\end{abstract}

Keywords: non-local damage, Thick Level Set, transverse cracking, composite laminates

\section{Introduction}

The appearance and development of transverse cracks in layered materials is an important problem in many fields of engineering, for example in composite laminates (Garret and Bailey, 1977; Highsmith and Reifsnider, 1982; Manders et al., 1983), thin-films (Thouless et al., 1992), civil engineering (Hong et al., 1997), or geology (Price, 1966). It is well established that in this configuration of layered materials, cracks tend to self-organize, with a spacing which is directly related to the relative thickness of layers. Explanations for this phenomenon, based on shielding effects, have been proposed on the basis of fracture mechanics (e.g. Bai and Pollard, 1999; Bai et al., 2000). This type of analysis relies on the study of the effect of discrete cracks placed in elastic layers, and although it can explain why a given crack distribution is optimal or natural in some way, it cannot provide details on the process which would lead to this crack distribution.

Transverse microcracking and local delamination in fiber-reinforced composite laminates have been studied mainly within the framework of finite fracture mechanics. Analytical approaches have been used for crack growth with energetic criteria that have allowed the definition of a large number of successful fracture models such as in Dvorak and Laws (1987), and others (Hashin,

*Corresponding author: laurent.stainier@ec-nantes.fr

Preprint submitted to Mechanics of Materials

May 11, 2015 
1996; Nairn, 2000; Varna et al., 1999). Rebière and Gamby (2004) recently proposed an analytical energetic criterion for modeling crack initiation and propagation in the matrix as well as delamination in cross-ply laminates. Alternatively, numerical models have been proposed to model matrix fracture, based on finite element approaches combined to bulk damage (Berthelot et al., 1996) or cohesive elements (Okabe et al., 2004). The meso-model developed by Ladevèze (Ladevèze and Lubineau, 2001; Ladevèze et al., 2006) predicts damage evolution directly at the ply level. Due to the variability of local material properties within the plies, the heterogeneity of mesoscopic structures must be considered. Some authors introduced a statistical criterion in strength like in Berthelot and Le Corre (2000), or a statistical criterion in toughness as in Andersons et al. (2008). Numerical studies of the propagation of debonding at the tip of transverse cracks were also treated by a variational approach to fracture (Baldelli et al., 2011).

Modeling the progressive degradation of materials from an initial undamaged state to total failure is still a challenge in computational mechanics. Damage models can be used to describe the initial degradation of mechanical properties, while fracture mechanics is well adapted to final stages leading to fracture. The Thick Level Set (TLS) approach, proposed by Moës et al. (2011), allows for a seamless transition between damage and fracture, while providing the necessary regularization in presence of softening.

In this paper, we present an analysis of the transverse cracking and interface failure process induced in layered materials (such as composite laminates) subjected to tensile loading, using the TLS approach. The main aspects of this method will be presented in section 2 . In section 3, a 2D finite element model is built to study damage in a cross-ply laminate. The study aims at evaluating the capacity of the TLS method to predict evolution of damage at the ply level, including initiation, propagation, merging of cracks or delamination. For this, we will start from undamaged (virgin) material with small but random variations of mechanical properties, and simulate the initiation and evolution of cracks. In section 4, we show how this numerical model is able to reproduce key features such as crack spacing saturation and other experimental observations. We also study the effect of some algorithmic parameters involved in the TLS method. The paper closes with some conclusions and perspectives.

\section{Thick Level Set (TLS) approach}

\subsection{Continuum damage}

Our objective in this work is to study the development of transverse cracks in layered materials, starting from a virgin (crack-free) state. It is nowadays well established that continuum damage models (CDM) are appropriate to treat early stages of material degradation. Abundant literature on CDM is available, which analysis is nonetheless beyond the scope of the present paper, and we will simply refer the reader to Lemaître et al. (2009).

\subsubsection{Local constitutive relations}

We will work under assumptions of linearized kinematics, and consider a simple elasticdamage model described by

$$
\sigma=\mathbb{C}(d): \boldsymbol{\varepsilon}
$$


where $\sigma$ is the Cauchy stress tensor, $\boldsymbol{\varepsilon}$ the engineering strain tensor, and $\mathbb{C}(d)$ a fourth-order elasticity tensor, function of the scalar damage variable $d \in[0,1]$. The model can alternatively be described in the framework of generalized standard materials (Halphen and Nguyen, 1975; Germain et al., 1983), by defining the free energy potential, a function of the material state $\{\boldsymbol{\varepsilon}, d\}$ :

$$
W(\varepsilon, d)=\frac{1}{2} \varepsilon: \mathbb{C}(d): \varepsilon .
$$

This potential in turn allows to define thermodynamical forces conjugate to state variables $\boldsymbol{\varepsilon}$ and $d$ :

$$
\begin{aligned}
& \boldsymbol{\sigma}=\frac{\partial W}{\partial \boldsymbol{\varepsilon}}(\boldsymbol{\varepsilon}, d) \\
& Y=-\frac{\partial W}{\partial d}(\boldsymbol{\varepsilon}, d)
\end{aligned}
$$

It is easily verified that (3) is equivalent to (1). Relation (4) defines the energy release rate $Y$, thermodynamically conjugate to damage $d$. The equation describing the evolution of damage is then obtained through the dissipation potential $\psi(Y)$ :

$$
\dot{d} \in \partial_{Y} \psi(Y)
$$

where $\partial_{Y} \psi$ denotes the sub-gradient of $\psi(Y)$, a (potentially non-regular) convex function of $Y$. Following standard arguments, convexity of $\psi(Y)$, combined to conditions $\psi(0)=0$ and $\psi(Y) \geq$ $0 \forall Y$, ensures positivity of the dissipation:

$$
\mathcal{D}=Y \dot{d} \geq 0
$$

This formalism allows to simultaneously cover both rate-independent and rate-dependent damage models. Indeed, the rate-independent case corresponds to a lower semi-continuous dissipation potential of the form:

$$
\psi(Y)= \begin{cases}0 & \text { if } Y \leq Y_{c} \\ +\infty & \text { if } Y>Y_{c}\end{cases}
$$

and (5) is then equivalent to Karush-Kuhn-Tucker conditions: $\dot{d} \geq 0, Y-Y_{c} \leq 0,\left(Y-Y_{c}\right) \dot{d}=0$. The rate-dependent case corresponds to more regular functions (e.g. power-law expressions of $Y$ or $Y-Y_{c}$ ). Finally, a dual dissipation potential $\psi^{*}$ can be defined through a Legendre-Fenchel transform:

$$
\psi^{*}(\dot{d})=\sup _{Y}[Y \dot{d}-\psi(Y)] \quad \text { and } \quad Y \in \partial_{\dot{d}} \psi^{*}(\dot{d})
$$

where convexity of $\psi^{*}(\dot{d})$ is guaranteed by properties of Legendre transforms.

\subsubsection{Boundary-value problem}

The boundary-value problem at a given time $t$ then consists in the static mechanical balance equation

$$
\boldsymbol{\nabla} \cdot \boldsymbol{\sigma}+\boldsymbol{b}=0 \quad \forall \boldsymbol{x} \in \Omega
$$


together with boundary conditions

$$
\begin{array}{rrr}
\boldsymbol{u} & =\overline{\boldsymbol{u}} & \forall \boldsymbol{x} \in \partial_{u} \Omega \\
\boldsymbol{\sigma} \cdot \boldsymbol{n} & =\overline{\boldsymbol{t}} & \forall \boldsymbol{x} \in \partial_{\sigma} \Omega
\end{array}
$$

where $\partial_{u} \Omega \bigcup \partial_{\sigma} \Omega=\partial \Omega$ and $\partial_{u} \Omega \bigcap \partial_{\sigma} \Omega=\emptyset$, and constitutive equations (3), (4), and (5). Vectors $\boldsymbol{b}, \overline{\boldsymbol{t}}$, and $\overline{\boldsymbol{u}}$ are respectively applied body force, applied surface traction, and imposed displacement at time $t$.

Alternatively, the boundary value problem can be stated in variational form:

$$
\operatorname{statinf}_{\dot{u}} \int_{\Omega}\left[\dot{W}\left(\boldsymbol{\nabla}^{s} \boldsymbol{u}, d\right)+\psi^{*}(\dot{d})\right] d V-\int_{\Omega} \boldsymbol{b} \cdot \dot{\boldsymbol{u}} d V-\int_{\partial \Omega_{\sigma}} \overline{\boldsymbol{t}} \cdot \dot{\boldsymbol{u}} d S
$$

where variations on $\dot{\boldsymbol{u}}$ must verify kinematic boundary conditions.

\subsection{Regularization}

The above problem is well known to lead to mathematical and numerical problems when strainsoftening occurs due to the development of damage. In particular spurious mesh dependency will appear, which can lead to damage propagation with infinitesimally small energy input in the limit. Introduction of non-local damage is known to regularize the problem (e.g. Pijaudier-Cabot and Bažant, 1987; Peerlings et al., 1996). Here, we will adopt the Thick Level Set (TLS) approach, proposed by Moës et al. (2011), and briefly summarized in this section.

The basic idea of the TLS method is to constrain damage distribution to follow a given profile in the transition zone between undamaged (virgin) and totally damaged zones. For this, a level set function $\phi$ is introduced, such that the curve $\Gamma_{0}: \phi=0$ separates virgin and damaged zones. The level set $\phi$ is then constructed as a distance function to $\Gamma_{0}$, and damage is constrained to the following distribution:

$$
\begin{aligned}
d(\phi)=0 & \text { where } \phi \leq 0 \\
0 \leq d(\phi) \leq 1 & \text { where } 0<\phi<l_{c} \\
d(\phi)=1 & \text { where } \phi \geq l_{c}
\end{aligned}
$$

as illustrated in figure 1. It appears clearly from the above definition that a length scale $l_{c}$ has now been introduced in the model: damage develops in a band bounded by $\Gamma_{0}$ and $\Gamma_{c}: \phi=l_{c}$ (the Thick Level Set) and the spatial distribution of $d$ is further constrained by the function $d(\phi)$.

Evolution of damage is now constrained by the evolution of level set $\phi$ (more precisely by the evolution of curve $\Gamma_{0}$ since $\phi$ is built as a distance function to $\Gamma_{0}$ ), and the variational boundaryvalue problem (11) becomes:

$$
\operatorname{stat}_{\dot{\boldsymbol{u}}} \inf _{\dot{\phi}} \int_{\Omega}\left[\dot{W}\left(\boldsymbol{\nabla}^{s} \boldsymbol{u}, d(\phi)\right)+\psi^{*}\left(d^{\prime}(\phi) \dot{\phi}\right)\right] d V-\int_{\Omega} \boldsymbol{b} \cdot \dot{\boldsymbol{u}} d V-\int_{\partial \Omega_{\sigma}} \overline{\boldsymbol{t}} \cdot \dot{\boldsymbol{u}} d S
$$

Concentrating on the minimization with respect to $\dot{\phi}$, we can write

$$
\inf _{\dot{\phi}} \int_{\Gamma_{0}} \int_{0}^{l_{c}}\left[-Y d^{\prime}(\phi) \dot{\phi}+\psi^{*}\left(d^{\prime}(\phi) \dot{\phi}\right)\right]\left(1-\frac{\phi}{\rho(s)}\right) d \phi d s
$$


where $s$ is a curvilinear coordinate along $\Gamma_{0}$ and $\rho(s)$ is the curvature radius of $\Gamma_{0}$ (see figure 2). Considering that $\phi$ is a distance function, we know that $\dot{\phi}=v_{n}$, where $v_{n}$ is the velocity of curve $\Gamma_{0}$ along the outward normal to the Thick Level Set zone (at $\phi=0$ ). The stationarity equation with respect to $\dot{\phi}$ (assuming conditions allowing progression of damage) then yields

$$
\int_{\Gamma_{0}} \int_{0}^{l_{c}}\left[-Y+\partial_{\dot{d}} \psi^{*}\left(d^{\prime}(\phi) \dot{\phi}\right)\right] d^{\prime}(\phi)\left(1-\frac{\phi}{\rho(s)}\right) \delta \phi d \phi d s=0 \quad \forall \delta \phi
$$

which can be rewritten as

$$
\int_{\Gamma_{0}}\left(-\bar{Y}+\bar{Y}_{c}\right)\left[\int_{0}^{l_{c}} d^{\prime}(\phi)\left(1-\frac{\phi}{\rho(s)}\right) d \phi\right] \delta \phi d s=0 \quad \forall \delta \phi
$$

where $\bar{Y}$ is defined by

$$
\bar{Y}=\frac{\int_{0}^{l_{c}} Y d^{\prime}(\phi)\left(1-\frac{\phi}{\rho(s)}\right) d \phi}{\int_{0}^{l_{c}} d^{\prime}(\phi)\left(1-\frac{\phi}{\rho(s)}\right) d \phi}
$$

and, assuming a rate-independent damage model such that

$$
\psi^{*}(\dot{d})= \begin{cases}Y_{c} \dot{d} & \text { if } \dot{d} \geq 0 \\ +\infty & \text { otherwise }\end{cases}
$$

$\bar{Y}_{c}$ is defined as

$$
\bar{Y}_{c}=\frac{\int_{0}^{l_{c}} Y_{c} d^{\prime}(\phi)\left(1-\frac{\phi}{\rho(s)}\right) d \phi}{\int_{0}^{l_{c}} d^{\prime}(\phi)\left(1-\frac{\phi}{\rho(s)}\right) d \phi} .
$$

The above equation shows that the evolution of the level set is controlled by an energy release rate which is averaged over the thickness of the damaged band (figure 3 ).

Note that average quantities defined by (17) and (19) are never explicitly evaluated. Instead, the quantity $\bar{Y}$ is evaluated by writing an associated variational problem, as detailed in Bernard et al. (2012).
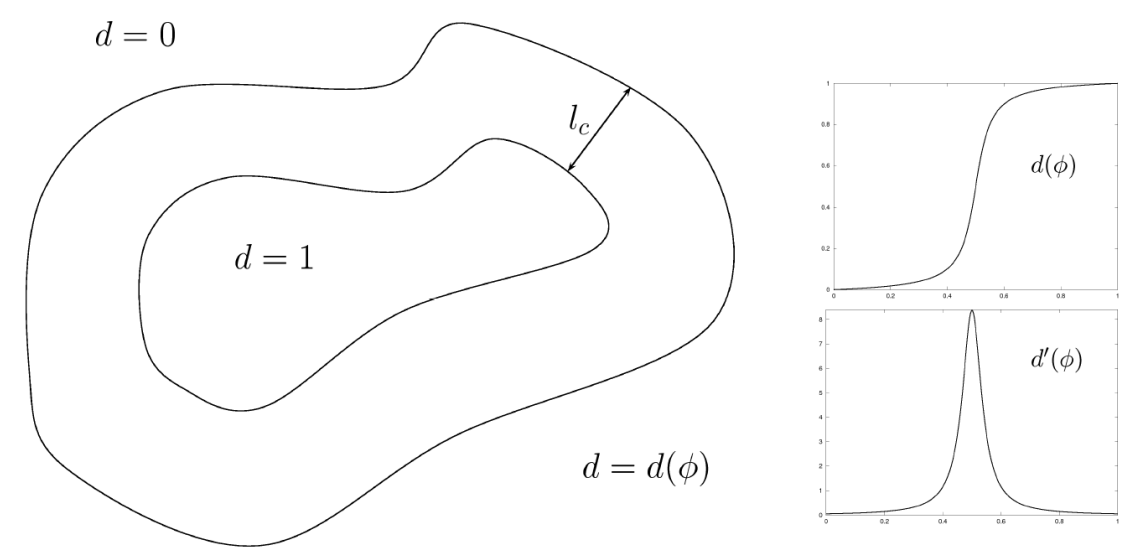

Figure 1: Damage distribution as defined by level set $\phi$ 


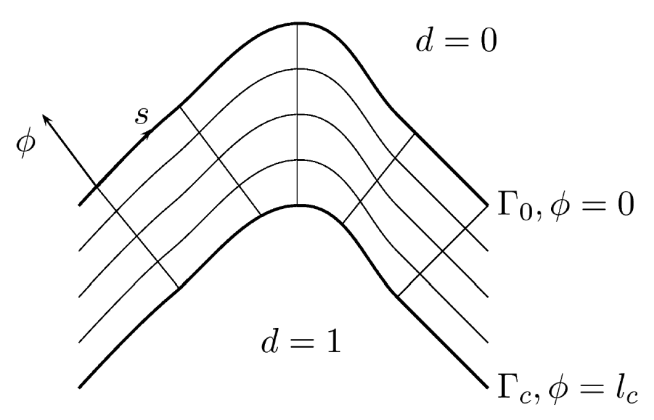

Figure 2: Parametrization on the Thick Level Set
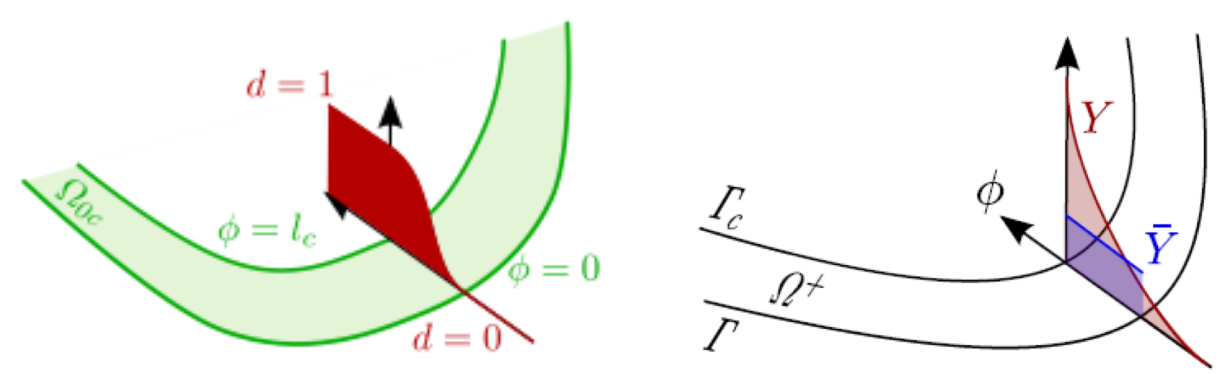

Figure 3: Definition of an average energy release rate $\bar{Y}$ over the damaged band

\subsection{Numerical algorithm}

The variational formulation described above concerns the rate problem. For numerical simulations, we need to adopt a time-discrete approach. For this purpose, we followed the strategy described in Bernard et al. (2012), summarized in Algorithm 1. This algorithm considers a quasistatic problem, with radial loading. The load factor $\mu$ is incrementally increased, and crack initiation and propagation is possible at each step. The algorithm computes load factor increments such that the damage front (curve $\Gamma_{0}$ ) advance $a$ is of the order of mesh size $h$. Front advance is chosen as proportional to $\left\langle\bar{Y}-\bar{Y}_{c}\right\rangle_{+}$(only forward motion is allowed, by irreversibility of damage), with a coefficient $k$ (see algorithm) computed from previous iterations. More details can be found in Bernard et al. (2012).

Note that the initiation criterion for new cracks is purely local. Once the local energy release rate $Y$ reaches a value above the local critical value $Y_{c}$, a small damaged zone is introduced around the critical point: for example, a level set corresponding to a circular curve $\Gamma$ of radius $r_{0}$ such that: $h<r_{0}<l_{c}$ (figure 4). Thus, this is not properly speaking a crack, but a small damaged zone, which can later develop as a fully formed crack, such evolution being controlled by a non-local criterion. Note also that damage initiation occurs in a range where the local constitutive behavior is mathematically well-posed (i.e. hardening stress-strain relation). Later stages are treated through the non-local TLS model, avoiding problems of pathological mesh dependence.

Some level of mesh adaption is required as damaged zones develop, in order to maintain a sufficiently accurate geometrical description of the level set (in particular in regions of strong 


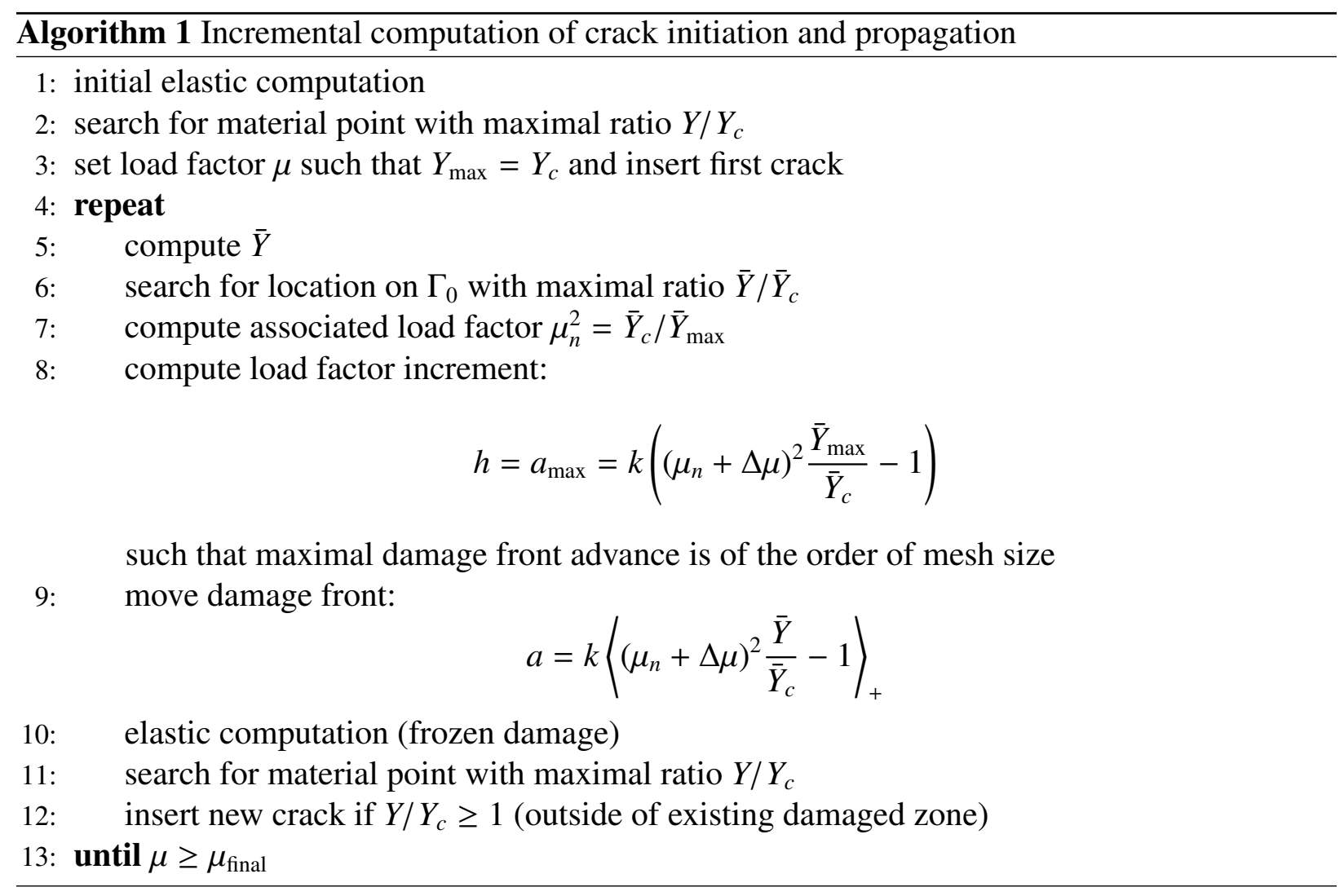

curvature, as in a crack tip), as well as for numerical integration purposes. This mesh adaption is performed by a recursive subdivision algorithm of quadtree type.

\section{Model laminate}

\subsection{Geometry and boundary conditions}

In the following, we will consider a composite laminate of type $\left[0_{m}^{\circ}, 90_{n}^{\circ}\right]_{s}$ corresponding to the stacking of unidirectional fiber reinforced plies at orthogonal directions, subject to uniaxial tension. Relative thicknesses of each layer are determined by the number $m$ and $n$ of unit plies introduced in the stacking sequence. In the configuration illustrated in figure 5, the fibers in the top and bottom layers are aligned with the tensile axis, and these layers will thus be considered as elastic, while fibers in the middle layer are orthogonal to the tensile direction, offering little resistance, and damage will develop in that region. Planar symmetries have been taken into consideration for the numerical model. Note that the amplitude of the applied tensile force is controlled by a load factor, itself computed by the algorithm 1 .

\subsection{Material properties}

The top and bottom layers are thus considered as purely elastic (no damage). Rigorously, an orthotropic elastic stiffness tensor should be used, with different elastic properties in the direction of fibers $\left(\boldsymbol{e}_{x}\right)$ and in the transverse direction $\left(\boldsymbol{e}_{y}\right)$. Nonetheless, considering that longitudinal 


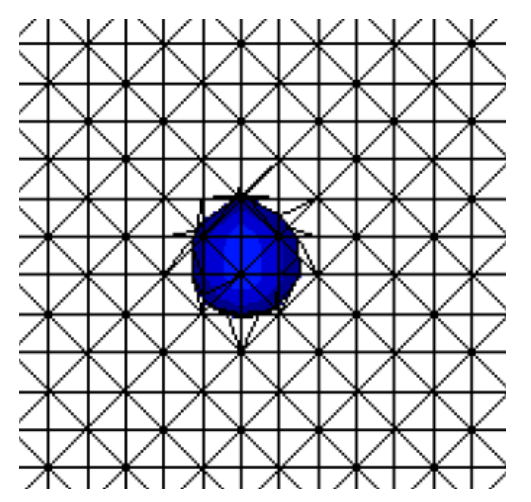

Figure 4: Initiation of a new damage zone
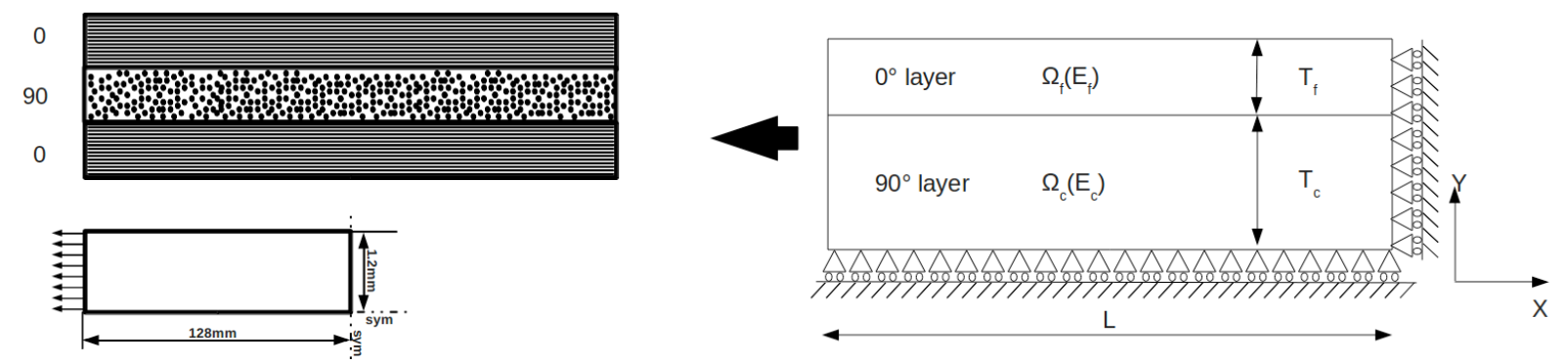

Figure 5: Geometry of model laminate

stresses will be dominant over transverse stresses, we will use an isotropic elasticity model with Young modulus $E_{f}$ and Poisson ratio $v$. For the central layer, the material can be considered as isotropic (transverse isotropy) with Young modulus $E_{c}<E_{f}$ and Poisson ratio $v$.

Damage (and cracks) can develop in the central layer, corresponding to matrix failure and/or fiber/matrix debonding. Despite the complexity of micro-mechanisms at work, we will use a simple scalar damage model. We will consider a damage evolution law allowing a progressive transition from undamaged $(d=0)$ to totally damaged $(d=1)$ states, as described by the following relation (Ladevèze and Le Dantec, 1992):

$$
d(t)=\max _{0 \leq \tau \leq t}\left\langle\frac{\sqrt{Y(\tau)}-\sqrt{Y_{0}}}{\sqrt{Y_{u}}-\sqrt{Y_{0}}}\right\rangle_{+}
$$

which can be reformulated through the dissipation pseudo-potential given by:

$$
\psi^{*}(\dot{d} ; d)=\left\{\begin{array}{ll}
Y_{c}(d) \dot{d} & \text { if } \dot{d} \geq 0 \\
+\infty & \text { otherwise }
\end{array} \quad \text { with } Y_{c}(d)=\left[\sqrt{Y_{0}}+d\left(\sqrt{Y_{u}}-\sqrt{Y_{0}}\right)\right]^{2}\right.
$$

where $Y_{0}$ is the (initial) critical energy release rate and $Y_{u}$ the ultimate energy release rate (i.e. at complete failure).

In order to account for heterogeneities in the material, we introduced a small variability for the critical energy release rate $Y_{0}$ in the central layer. This heterogeneity is due to variations in the density and/or orientation of fibers, as well as other defects, resulting in zones of weaker 
and higher strength. This variability affects both initiation and propagation of the cracks in the layer. Various distribution are used in the literature, the use of a particular distribution depending on the composite and on the physical process considered. Here, following Berthelot and Le Corre (2000), we chose a pseudo-normal distribution (i.e. a normal distribution, but defined on a bounded domain), but applied on the critical energy release rate (instead of the critical stress in the original paper), yielding

$$
Y_{0}=(\sigma N(0,1)+1) \tilde{Y}_{0}
$$

where $N(0,1)$ is the normal distribution function, $\sigma$ the standard deviation, and $\tilde{Y}_{0}$ the average value of critical energy release rate. In the following, unless explicitly indicated otherwise, we will use a standard deviation of $\sigma=0.19$. In practice, we obtain a discrete distribution, by drawing a value for each element of the mesh, yielding the distribution illustrated on figure 6. Keeping in line with Berthelot and Le Corre (2000), a "tail" with particularly weak values of $Y_{c}$ was added to the normal distribution to account for micro-cavities which are known to occur in real materials. Berthelot and Le Corre showed that such weak zones were necessary to reproduce more accurately crack density evolution curves in their initial stages.

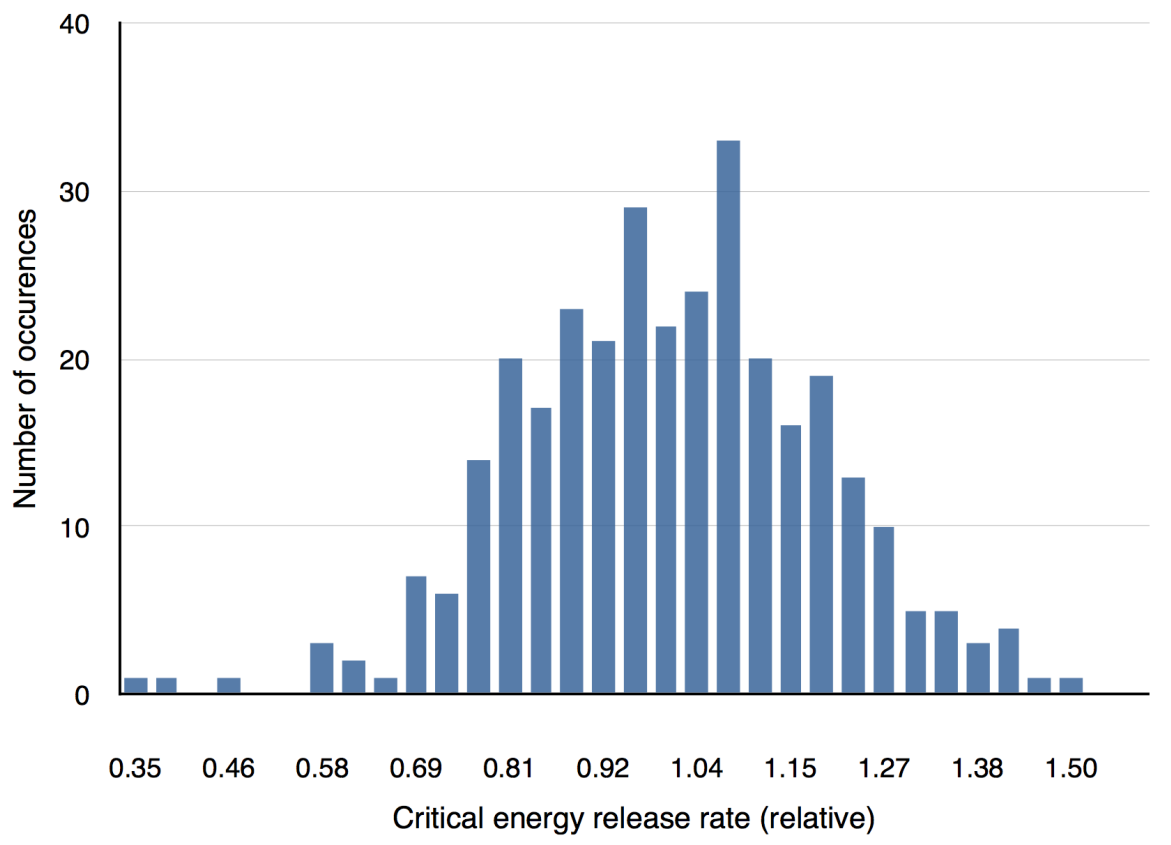

Figure 6: Distribution of the relative critical energy release rate $Y_{c} / \tilde{Y}_{c}$ over elements of the central layer

The average critical energy release rate $\tilde{Y}_{0}$ is itself computed from the fracture energy $G_{c}$ by considering the following relation:

$$
G_{c}=Y_{c} l_{c} \Longleftrightarrow \tilde{Y}_{0}=\frac{\tilde{G}_{c}}{l_{c}}
$$

where $\tilde{G}_{c}$ is the average fracture energy. 


\section{Results}

\subsection{Influence of algorithmic parameters}

In order to assess the effect of algorithmic parameters introduced by the TLS (i.e. $d(\phi)$ and $\left.l_{c}\right)$, we consider the case studied by Garret and Bailey (1977): a glass/polyester cross-ply composite, with individual plies of thickness $0.8 \mathrm{~mm}$ and mechanical properties listed in table 1 . The laminate is subjected to tensile loading in the direction corresponding to the orientation of fibers in the top and bottom layers. Note that our numerical model assumes plane strains. The initial mesh size is of the order of $0.05 \mathrm{~mm}$.

Table 1: Material properties for a glass/polyester composite

\begin{tabular}{ccccc}
\hline$E_{f}(\mathrm{GPa})$ & $E_{c}(\mathrm{GPa})$ & $v$ & $\tilde{Y}_{0}(\mathrm{MPa})$ & $Y_{u}(\mathrm{MPa})$ \\
\hline 23.0 & 4.2 & 0.3 & 0.057 & 1.3 \\
\hline
\end{tabular}

Given the heterogeneity of the critical energy release rate $Y_{c}$, damage will first develop in a well localized zone, forming a first crack, followed by others as the applied stress increases. Cracks will appear at a distance from each other (as discussed below), leading to a distribution as illustrated in figure 7. Note that adaptive mesh refinement has led to about 40000 degrees of freedom at this final stage.

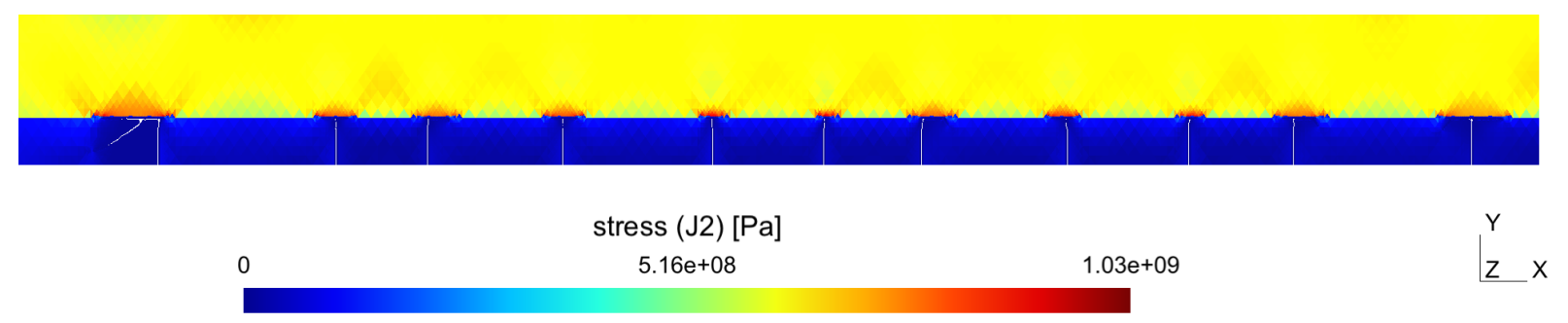

Figure 7: Transverse crack propagation in a $[0,90,0]$ glass/polyester laminate.

\subsubsection{Damage profile}

Before looking at predictions of our numerical model, we can study the effect of algorithmic parameters introduced by the TLS approach. First, we will consider a fixed characteristic length, of the order of the diameter of a fiber $\left(l_{c}=15 \mu \mathrm{m}\right)$, and vary the shape of damage function $d(\phi)$. Various possibilities are illustrated in figure 8.

One interesting indicator for comparing results is the crack density at the final stage: in computing this density, we considered only cracks that have propagated through the middle layer. The final stage can be defined as the stress level for which no more transverse cracks appear, propagation of damage occurring instead along the interface between the two layers. Results for this indicator are given in table 2 . These results indicate that the linear and arctan2 profiles provide the best fit with respect to experimental measures. The polynomial profiles lead to very low numbers: in these cases, new damaged zones seem to be more easily initiated, preventing existing damaged zones to develop as actual, propagated, cracks. 


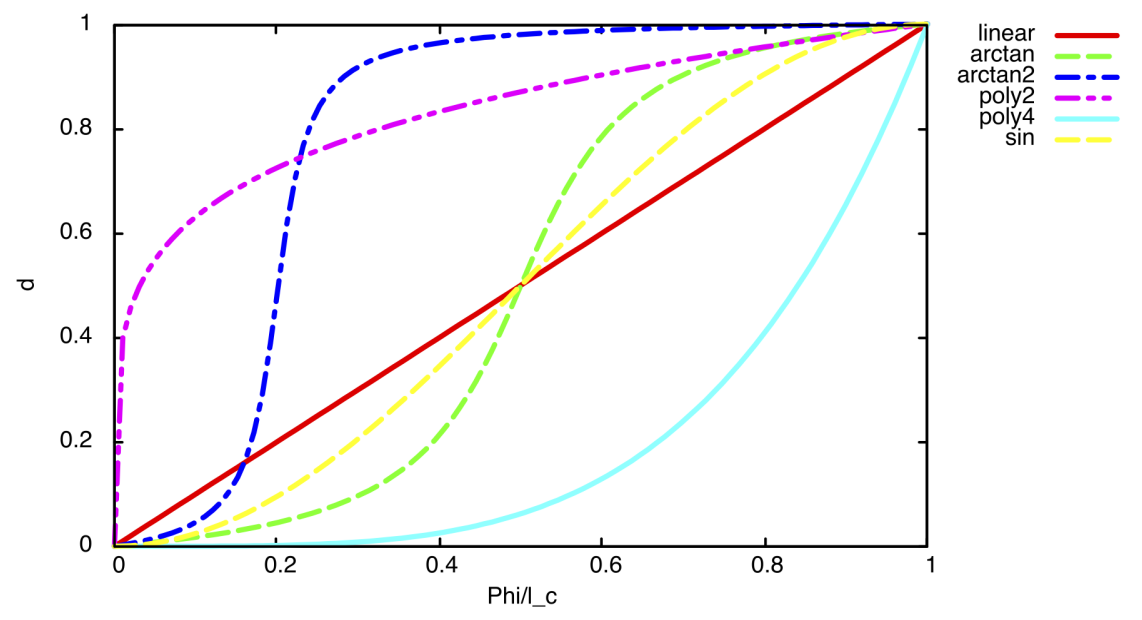

Figure 8: Various damage profiles $d(\phi)$

Table 2: Final crack density in function of damage profile $d(\phi)$

\begin{tabular}{|c|c|c|}
\hline Label & Profile & Crack density $\left(\mathrm{m}^{-1}\right)$ \\
\hline linear & $d(\phi)=\frac{\phi}{l_{c}}$ & $\approx 1000$ \\
\hline $\arctan$ & $d(\phi)=\frac{1}{2 \arctan (5)} \arctan \left[10\left(\frac{\phi}{l_{c}}-0.5\right)\right]+0.5$ & $\approx 750$ \\
\hline $\arctan 2$ & $d(\phi)=\frac{\arctan \left[35\left(\frac{\phi}{l_{c}}-0.2\right)\right]+\arctan (7.0)}{\arctan (28.0)+\arctan (7.0)}$ & $\approx 1000$ \\
\hline poly2 & $d(\phi)=\left(\frac{\phi}{l_{c}}\right)^{0.2}$ & $\approx 0$ \\
\hline poly4 & $d(\phi)=\left(\frac{\phi}{l_{c}}\right)^{4}$ & $\approx 0$ \\
\hline sin & $d(\phi)=0.5 \sin \left(\pi\left(\frac{\phi}{l_{c}}-0.5\right)\right)+0.5$ & $\approx 250$ \\
\hline reference & Garret and Bailey $(1977)$ & $\approx 1000$ \\
\hline
\end{tabular}

Restricting the focus on the two damage profiles better predicting the crack density, we can look in more details at the distribution of damage around a typical crack tip. As illustrated in figure 9, the linear profile leads to a sharper damage distribution, while the arctan2 profile leads to a well visible "process-zone" ahead of the crack tip. The difference is associated to the local curvature radius of the level set describing the damage front: a small $\left(<l_{c}\right)$ curvature radius leads to a thin $\left(<2 l_{c}\right)$ damage zone, where damage remains lower than the limit value one everywhere, corresponding to a "process-zone", while a larger $\left(>l_{c}\right)$ curvature radius allows for a wider $\left(>2 l_{c}\right)$ damage zone in the center of which damage can reach a value of one, corresponding to a crack. The "process-zone" seems to correspond better to what is observed experimentally, with a transition from somewhat diffuse damage to a crack, and in the following we will thus retain the arctan2 
profile for $d(\phi)$.

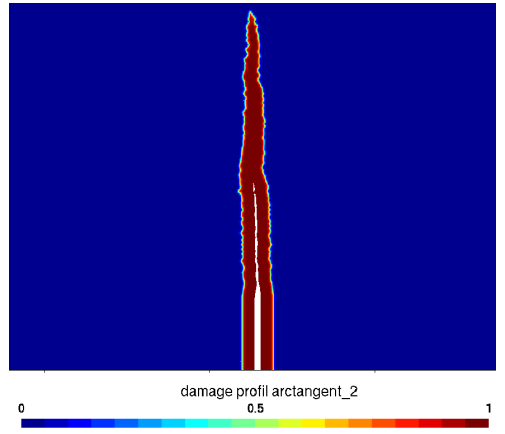

(a) $\arctan 2$

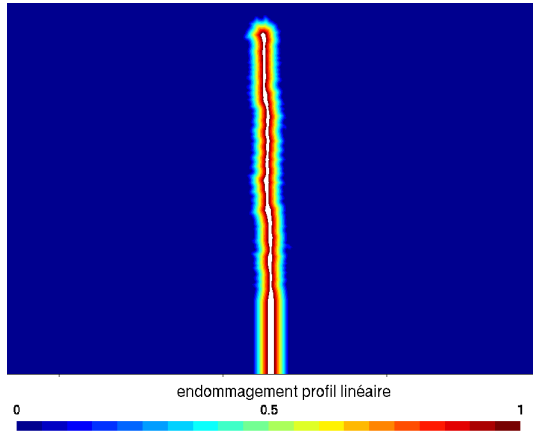

(b) linear

Figure 9: Effect of damage profile on crack tip distribution (both figures are not to scale)

\subsubsection{Characteristic length}

Considering a fixed damage profile, chosen as the arctan2 expression above, we can now study the effect of the characteristic length $l_{c}$. We have run the same simulation, with values of $l_{c}=10 \mu \mathrm{m}, l_{c}=15 \mu \mathrm{m}$, and $l_{c}=20 \mu \mathrm{m}$. Results can be compared in terms of crack density evolution in function of applied stress, as illustrated in figure 10, for various stacking sequences (corresponding to different thickness ratios). We can first observe that the parameter $l_{c}$ does not seem to have a significant effect on results. Then, numerical results present a relatively good agreement with experimental results of Garret and Bailey (1977). The main difference appears for the case of the $\left[0^{\circ}, 90^{\circ}, 0^{\circ}\right]$ laminate, but it must be emphasized that a better fit can actually be obtained by playing with the statistical distribution of $Y_{c}$. Indeed, increasing the value of standard deviation up to $\sigma=0.5$ can flatten the crack density curves, as shown in figure 11, and a translation can be obtained by varying the average value $\tilde{Y}_{0}$.

\subsection{Comparison with experimental data}

\subsubsection{Crack saturation}

In multi-layered materials, with layers of different mechanical properties subjected to tensile stress in the longitudinal direction, transverse cracks will appear, parallel to each others. These cracks appear in the weaker layers, and are confined by neighboring stronger layers. When longitudinal stress/strain increase, the number of cracks increases as well, with new cracks nucleating between existing ones, up to a certain threshold, beyond which no more cracks appear. This saturation state is characterized by the distance between cracks. It has been experimentally observed (Garret and Bailey, 1977; Parvizi et al., 1978; Wu and Pollard, 1995) that this distance is related to the relative thickness of the weak layer with respect to the strong layer.

In the following, we will verify that our numerical model is able to reproduce this kind of behavior. For this purpose, we consider a laminate with material properties listed in table 3 . Within this preliminary study, we will adopt a strategy slightly different from what was exposed before, in order to accelerate numerical computations (several successive computations had to be run), and to have a more precise control on crack development. Thus, a number of transverse "pre-cracks" 


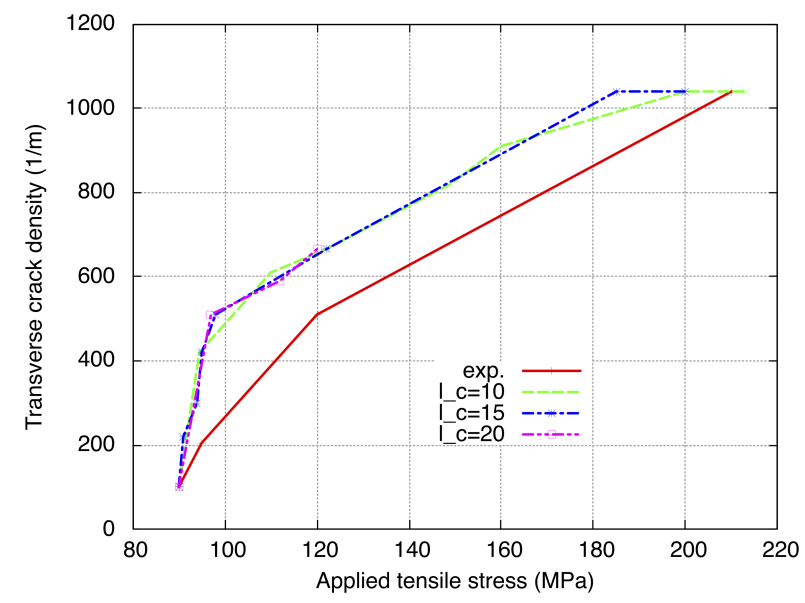

(a) $[0,90,0]$ laminate

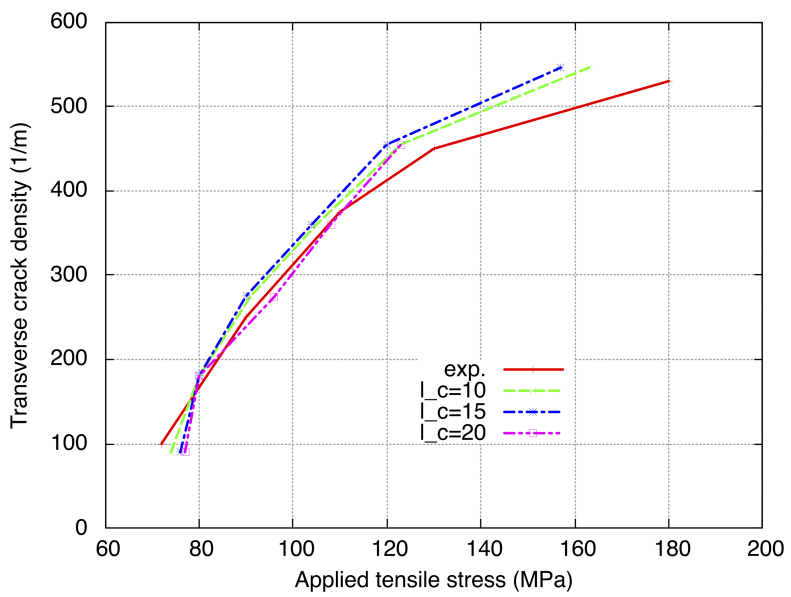

(b) $\left[0,90_{2}, 0\right]$ laminate

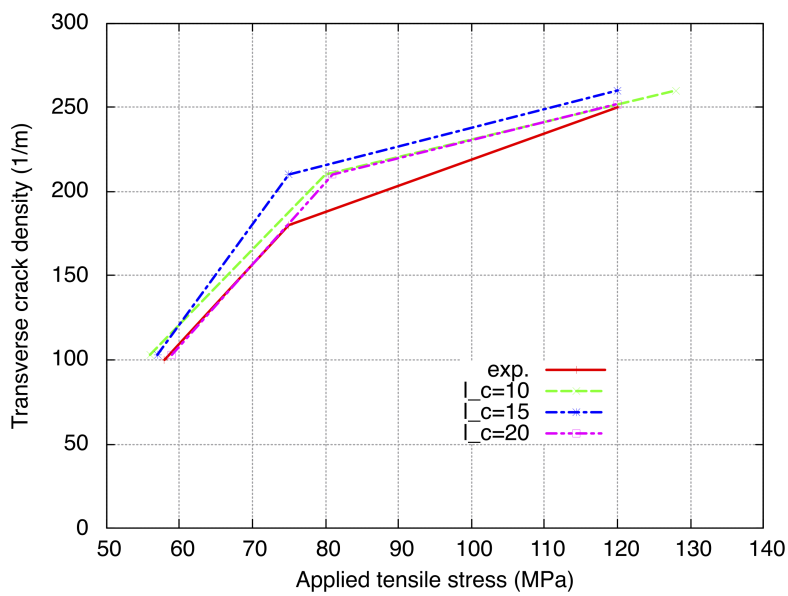

(c) $\left[0,90_{4}, 0\right]$ laminate

Figure 10: Crack density vs. applied stress: experimental measures (Garret and Bailey, 1977) and numerical results for various $l_{c}$ (given in $\mu \mathrm{m}$ ) 


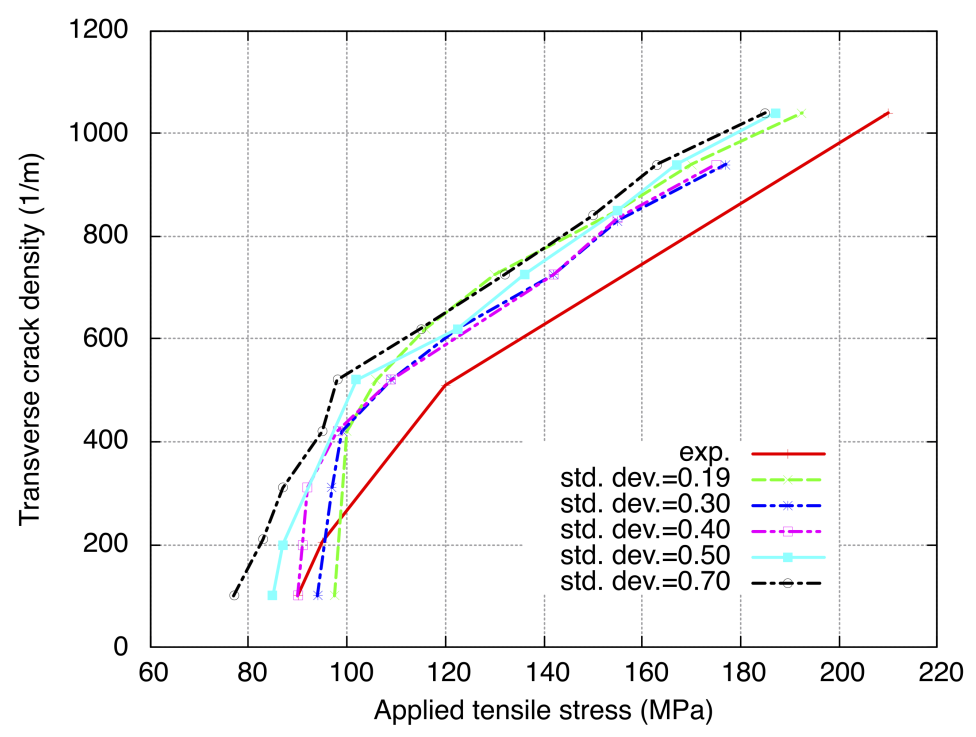

Figure 11: Influence of standard deviation $\sigma$ on evolution of crack density with applied stress (with $\left.\tilde{Y}_{0}=0.062 \mathrm{MPa}\right)$

(i.e. damaged zones extending over one fourth of the central layer's thickness) is introduced at a given distance of each others. Depending on the thickness of the strong $\left(0^{\circ}\right)$ and weak $\left(90^{\circ}\right)$ layers, some of these cracks will evolve to become fully developed transverse cracks, while some others not. In this approach, it is then not necessary to introduce variability in the critical energy release rate. For various thickness ratio between the strong and weak layers, several simulations were run, with varying spacing between the pre-cracks (arbitrarily chosen of length equal to one fourth of the central layer's thickness), to identify which are the ones where all pre-cracks propagated across the whole thickness. From this batch of simulations, we could associate crack spacing and thickness ratio. The results are given in figure 12, where they are compared to results of Bai and Pollard (1999). This plot shows how the relative (transverse) crack spacing decreases when the ration of thickness between the outer and inner layers increases (i.e. the central layer becomes more and more confined). We can see that the agreement between our results and those from the reference is reasonably good: the saturation is well captured, as well as the increase of the relative crack spacing at lower values of thickness ratio. A potential explanation for the difference may be that Bai and Pollard (1999) used a different ratio of elastic moduli, although they also point out that the influence of that factor should be relatively limited.

Table 3: Material properties for crack saturation tests

\begin{tabular}{cccc}
\hline$E_{f}(\mathrm{GPa})$ & $E_{c}(\mathrm{GPa})$ & $v$ & $Y_{0}(\mathrm{MPa})$ \\
\hline 130.0 & 13.0 & 0.3 & 0.05 \\
\hline
\end{tabular}

\subsubsection{Glass/epoxy laminates}

With respect to material properties previously used for the glass fiber laminate considered when studying algorithmic parameters, the statistical distribution of $Y_{0}$ has been adjusted by in- 


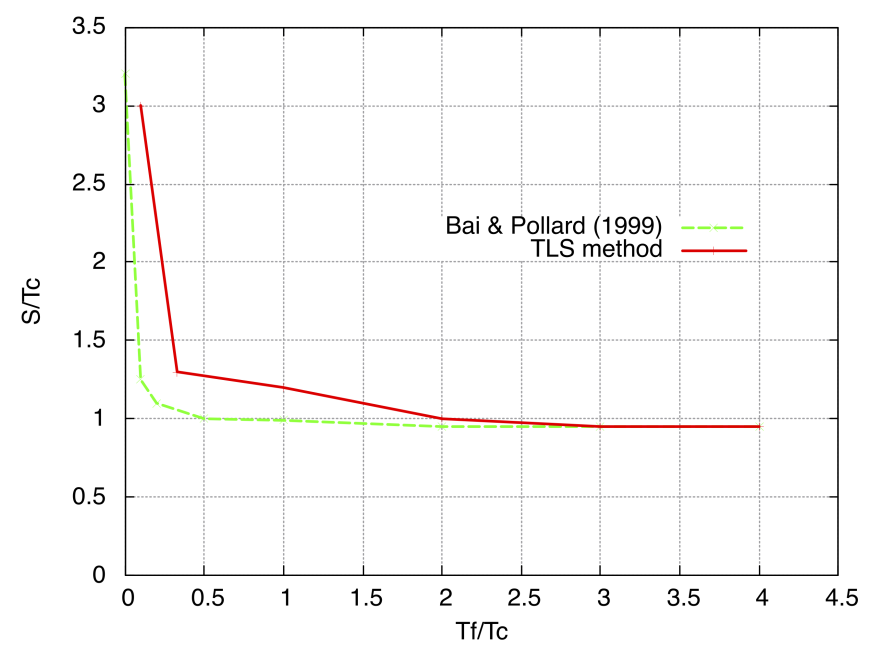

Figure 12: Crack saturation effect: comparison with results from Bai and Pollard (1999) ( $S$ is the crack spacing, $T_{f}$ and $T_{c}$ are outer and inner layers' thickness as defined in fig. 5)

creasing standard deviation $\sigma$ and average critical energy release rate $\tilde{Y}_{0}$ to better fit experimental crack density curves: looking at figure 11 , increasing the value of $\tilde{Y}_{0}$ allows to shift the curve corresponding to $\sigma=0.7$ on top of the experimental curve. Note that the value of $Y_{u}$ is basically linked to the ultimate strength of the epoxy matrix. The resulting set of data is listed in table 4 .

Table 4: Material properties for a glass/epoxy composite

\begin{tabular}{cccccc}
\hline$E_{f}(\mathrm{GPa})$ & $E_{c}(\mathrm{GPa})$ & $v$ & $\tilde{Y}_{0}(\mathrm{MPa})$ & $\sigma$ & $Y_{u}(\mathrm{MPa})$ \\
\hline 23.0 & 4.2 & 0.3 & 0.08 & 0.7 & 1.3 \\
\hline
\end{tabular}

Results obtained from simulations performed with this adjusted set of parameters are shown in figure 13. We can observe the appearance of successive transverse cracks in the weaker central layer, as the average longitudinal strain increases. New cracks typically initiate at the core of the laminate and propagate until they reach the interface between the $90^{\circ}$ and $0^{\circ}$ layers. One can clearly see on this figure that, as new cracks appear, they tend to respect a spacing equivalent to the (weak) layer's thickness (remember that the simulation takes advantage of the transverse symmetry), which will ultimately lead to saturation (not reached in the numerical simulation presented here) as previously discussed.

Figure 14 plots the evolution of transverse crack density as a function of applied longitudinal stress, for various stacking sequences (of type $\left[0^{\circ}, 90_{n}^{\circ}, 0^{\circ}\right]$ ) corresponding to a variable thickness ratio between strong and weak layers. These curves are compared with results from Garret and Bailey (1977), and exhibit an excellent agreement with this reference.

\subsubsection{Carbon fiber reinforced laminates}

We have also considered a the case of carbon fiber reinforced laminates, with an epoxy matrix. This configuration presents a stronger elastic stiffness ratio between longitudinal $\left(0^{\circ}\right)$ and transverse $\left(90^{\circ}\right)$ directions, as can be seen in table 5. Reference results for this type of laminates are 


$$
\bar{\varepsilon}_{x x}=0.4 \%\left(\bar{\sigma}_{x x}=79 \mathrm{MPa}\right)
$$

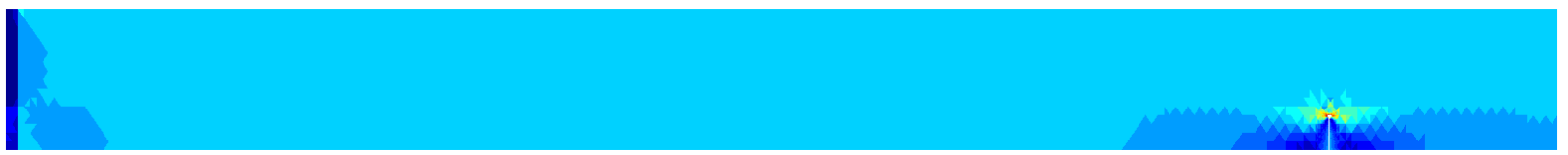

$$
\bar{\varepsilon}_{x x}=0.41 \%\left(\bar{\sigma}_{x x}=80 \mathrm{MPa}\right)
$$

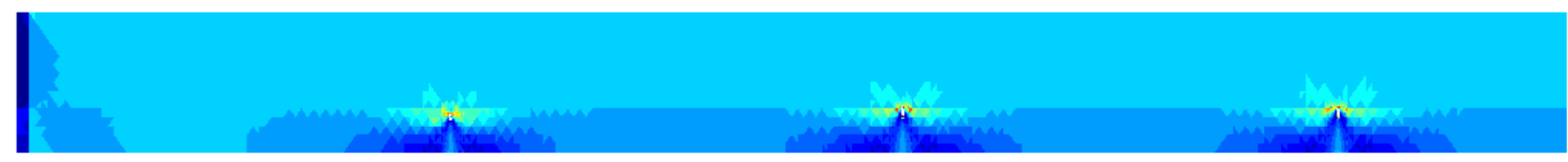

$$
\bar{\varepsilon}_{x x}=0.45 \%\left(\bar{\sigma}_{x x}=85 \mathrm{MPa}\right)
$$

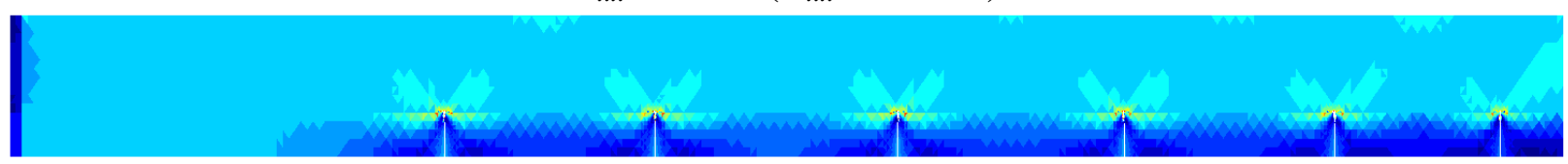

$$
\bar{\varepsilon}_{x x}=0.49 \%\left(\bar{\sigma}_{x x}=90 \mathrm{MPa}\right)
$$

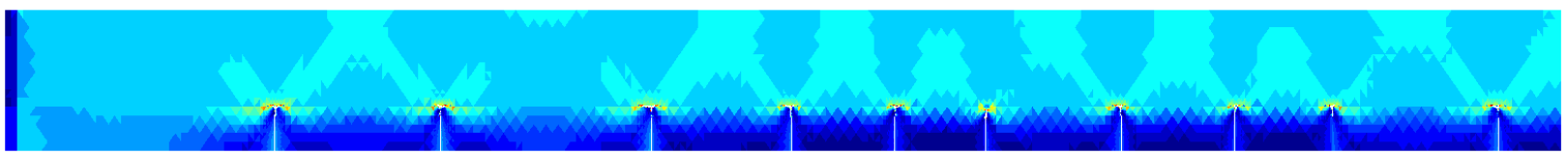

$$
\bar{\varepsilon}_{x x}=1 \%\left(\bar{\sigma}_{x x}=175 \mathrm{MPa}\right)
$$

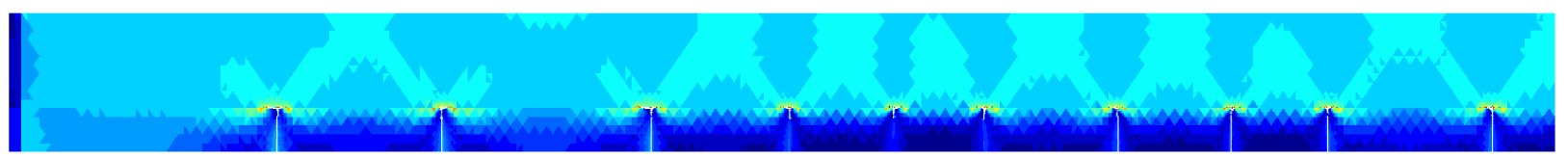

$$
\bar{\varepsilon}_{x x}=1.2 \%\left(\bar{\sigma}_{x x}=210 \mathrm{MPa}\right)
$$

Figure 13: $\left[0^{\circ}, 90^{\circ}, 0^{\circ}\right]$ glass/epoxy laminate: transverse cracks evolution as a function of longitudinal strain. Average tensile stress has also be indicated for reference. Color map corresponds to strains.

available in the experimental work of Wang (1984), for example. Here again, parameters describing the statistical distribution of the critical energy release rate have been chosen so as to adjust the crack density evolution curves: in particular the choice of $\tilde{Y}_{0}$ allows to set the tensile stress at which transverse cracks start to develop significantly.

Table 5: Material properties for a carbon/epoxy composite

\begin{tabular}{cccccc}
\hline$E_{f}(\mathrm{GPa})$ & $E_{c}(\mathrm{GPa})$ & $v$ & $\tilde{Y}_{0}(\mathrm{MPa})$ & $\sigma$ & $Y_{u}(\mathrm{MPa})$ \\
\hline 76.0 & 11.7 & 0.29 & 0.98 & 0.7 & 1.3 \\
\hline
\end{tabular}

Figure 15 shows the evolution of transverse cracks with increasing longitudinal strain, as predicted by the numerical simulations. Again, the transverse cracks are well seen to appear at a 


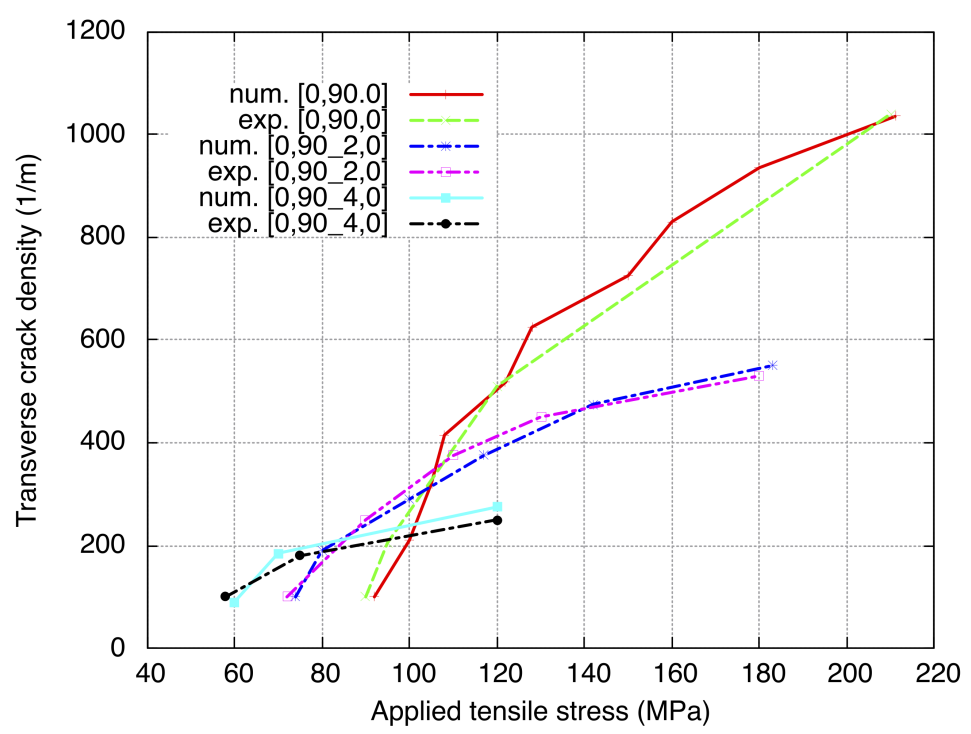

Figure 14: Glass/epoxy laminates: crack density evolution with longitudinal stress and comparison with experimental data from Garret and Bailey (1977)

regular distance from each other, as expected. The evolution of transverse crack density with longitudinal stress is shown on figure 16, for various relative thickness of the laminate layers. Numerical results show a good agreement with experimental measures from Wang (1984).
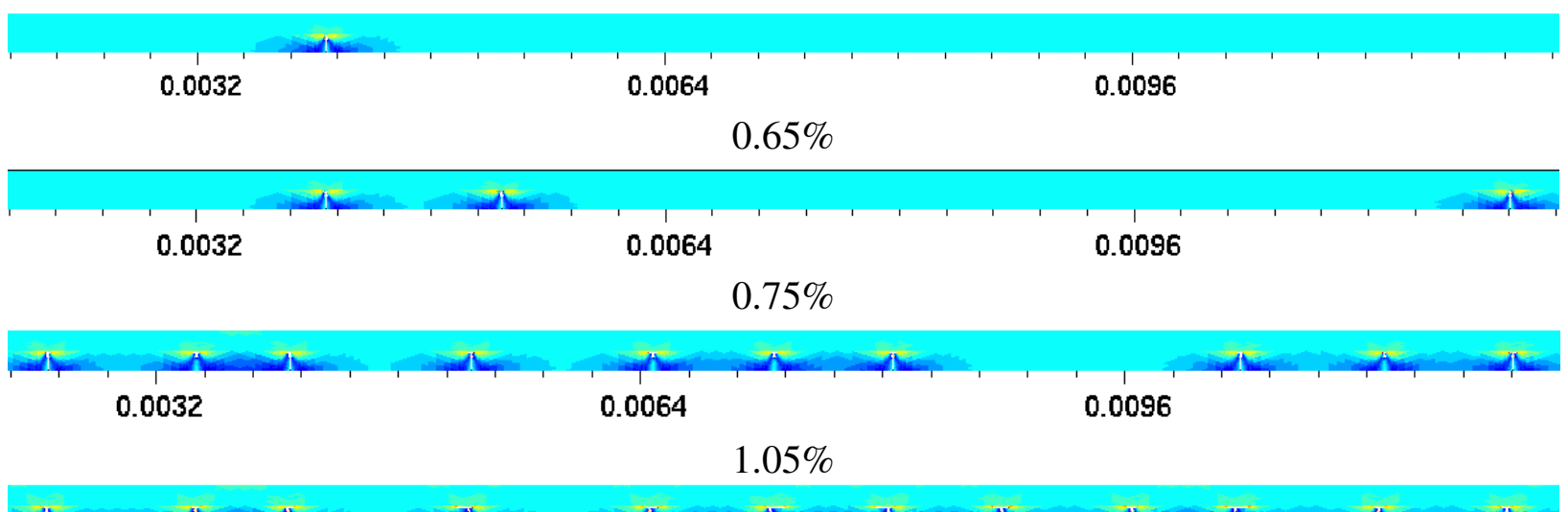

$$
0.0032
$$

\section{$1.4 \%$}

Figure 15: $\left[0^{\circ}, 90_{2}^{\circ}, 0^{\circ}\right]$ carbon/epoxy laminate: transverse cracks evolution as a function of longitudinal strain. Color map corresponds to strains, the ruler corresponds to longitudinal coordinate.

Note that in this example, before full saturation of transverse cracks (i.e. for an average longitudinal strain of about $1.4 \%$, as illustrated in fig. 15), damage propagates along the interface between layers, in what resembles a delamination process (see figure 17). This behavior, not observed in the previous example, can probably be related to the stronger contrast between the elastic moduli of the strong and weak layers. Note however that the actual capacity of the TLS approach 


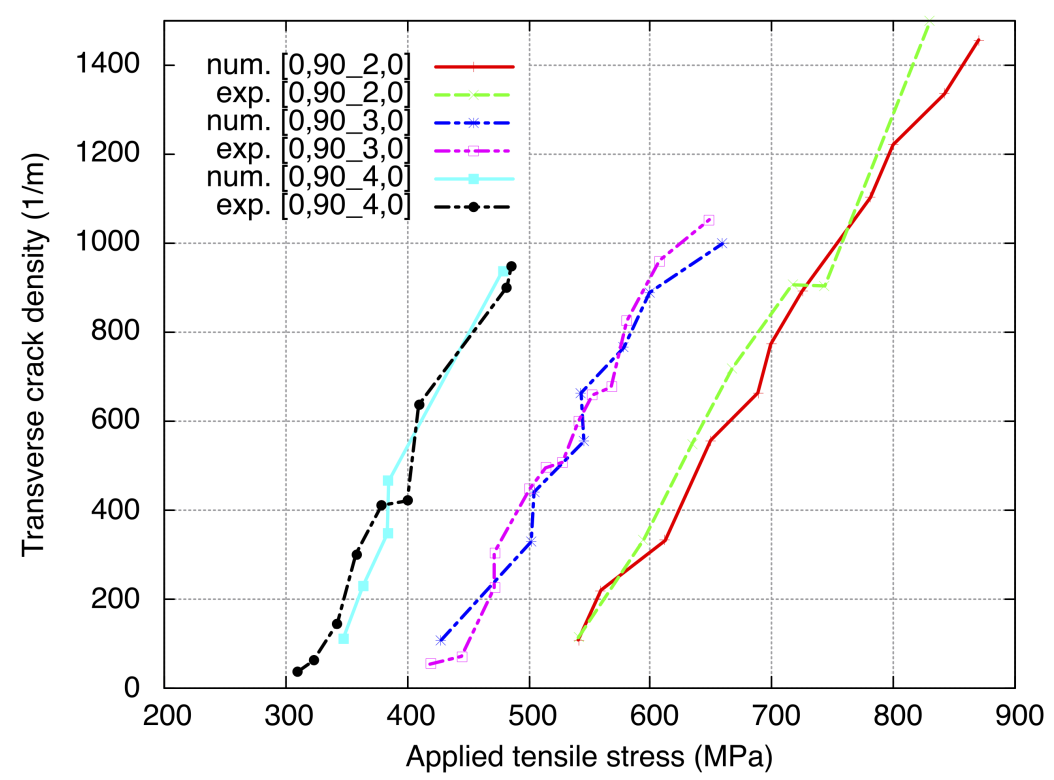

Figure 16: Carbon/epoxy laminates: crack density evolution with longitudinal stress and comparison with experimental data from Wang (1984)

to reproduce delamination is still the object of ongoing work. These delamination results thus remain mostly qualitative at this stage.

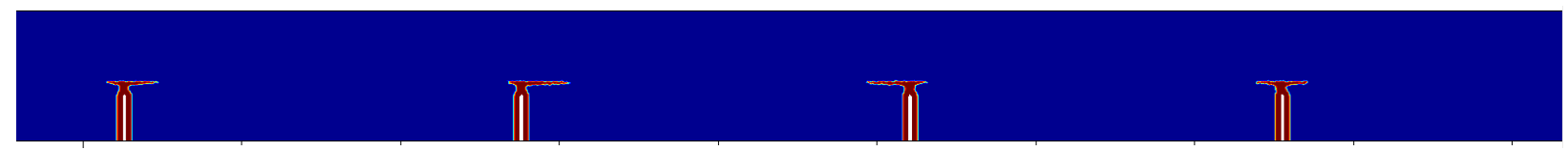

Figure 17: Damage propagation along the interface in a carbon/epoxy laminate (color map indicates damage: blue is virgin material, red is damaged material)

\subsection{4. $\left[90_{m}^{\circ}, 0_{n}^{\circ}\right]_{s}$ laminates}

As a final application of the proposed numerical modeling approach, we now consider a configuration where the weak layers (i.e. the $90^{\circ}$ plies) are located on the laminate's skin. This setting has been studied by Okabe et al. (2008), for example, for a glass/epoxy composite with properties listed in table 6. Note that in this configuration, transverse cracks that will appear on the top and bottom plies will not be aligned (they will actually alternate, see figure 18), and it is thus not possible to take advantage of the apparent geometrical symmetry of the problem.

Table 6: Material properties for a glass fiber composite

\begin{tabular}{ccccc}
\hline$E_{f}(\mathrm{GPa})$ & $E_{c}(\mathrm{GPa})$ & $v$ & $\tilde{Y}_{0}(\mathrm{MPa})$ & $Y_{u}(\mathrm{MPa})$ \\
\hline 30.0 & 9.6 & 0.31 & 0.33 & 4.0 \\
\hline
\end{tabular}

Figure 18 shows the evolution of the transverse cracks pattern in a $\left[90^{\circ}, 0^{\circ}, 90^{\circ}\right]$ laminate. One can see new cracks appearing alternatively on the bottom or top layer, positioning themselves in 
a nonaligned fashion, as expected. The spacing at crack saturation depends, here as well, on the relative thickness of each kind of layer, as it is well visible on figure 18.
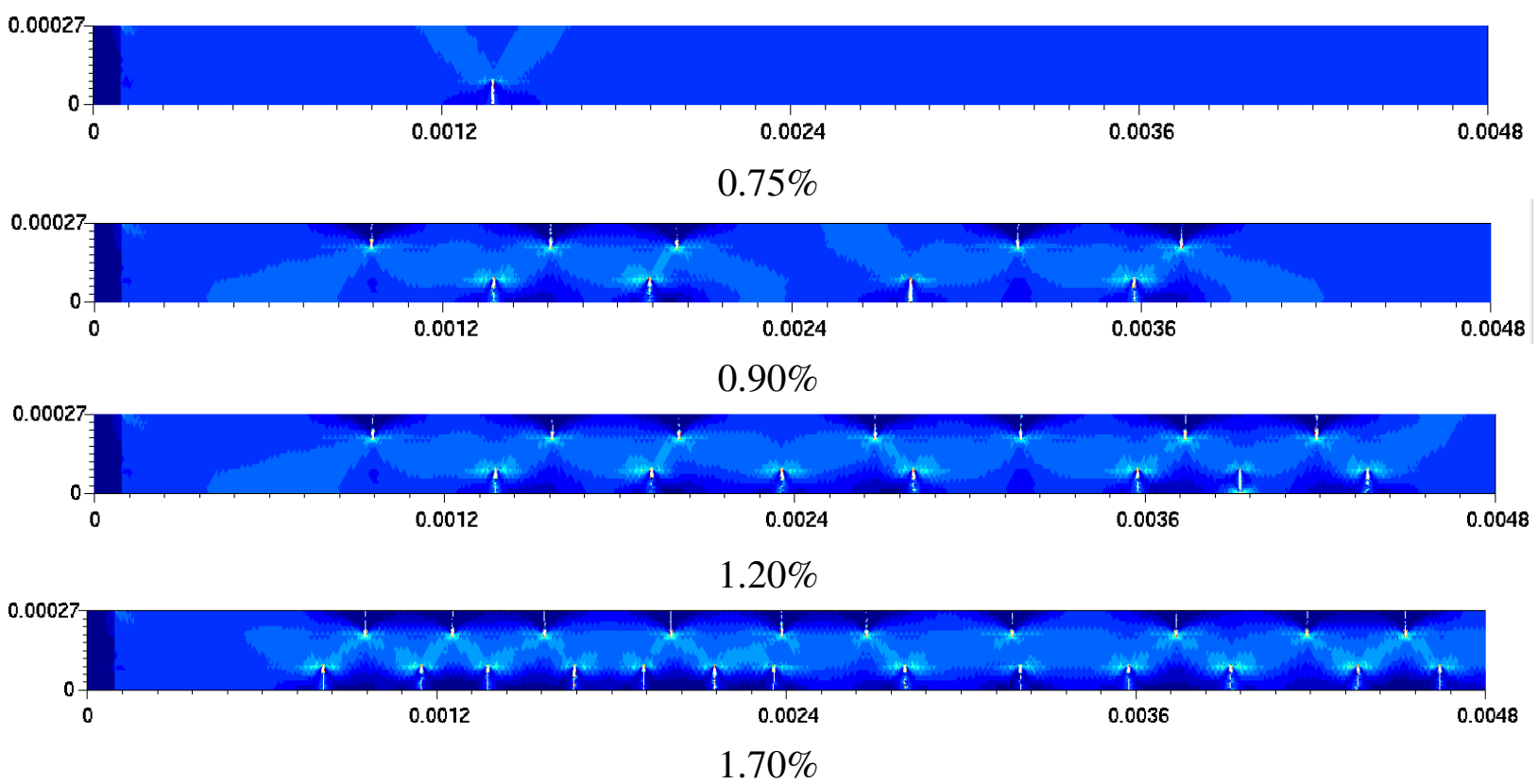

Figure 18: $\left[90^{\circ}, 0^{\circ}, 90^{\circ}\right]$ glass/epoxy laminate: transverse crack evolution as a function of average longitudinal strain (the ruler corresponds to longitudinal coordinate)
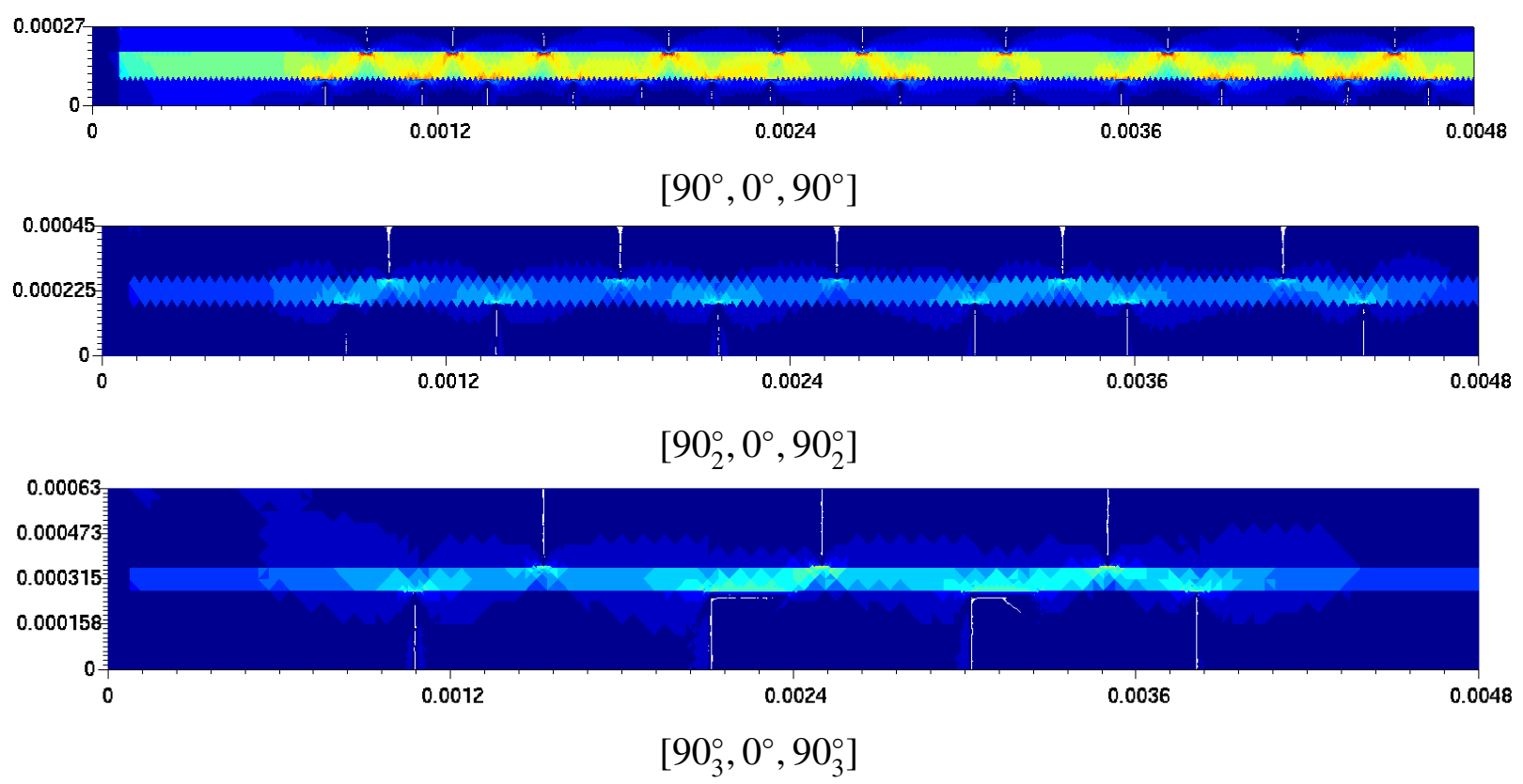

Figure 19: Final transverse crack distribution in glass/epoxy laminates with different stacking sequences (the ruler corresponds to longitudinal coordinate) 
In terms of a more quantitative comparison, figure 20 shows the evolution of transverse cracks density as a function of longitudinal stress, for various stacking arrangements. These numerical results are compared to data from Okabe et al. (2008), again with a very good agreement.

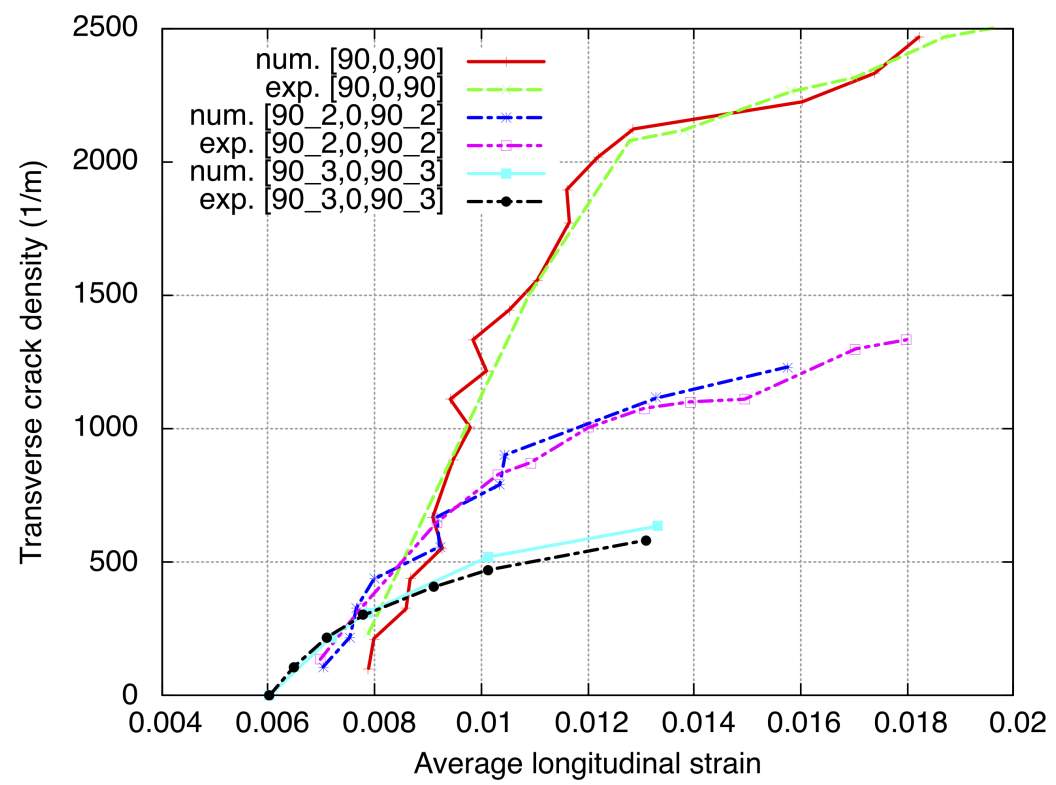

Figure 20: $\left[90_{n}^{\circ}, 0^{\circ}, 90_{n}^{\circ}\right]$ glass/epoxy laminates: crack density evolution with average longitudinal strain, and comparison with experimental data from Okabe et al. (2008)

\section{Conclusion}

In this paper, we have presented an application of the Thick Level Set (TLS) method (Moës et al., 2011; Bernard et al., 2012) to numerical studies of the development of transverse cracks in multilayered materials, and in particular in composite laminates. The TLS approach solves several difficulties associated to numerical modeling of damage and transition between localized damage and fracture, such as the capacity to include crack initiation and branching, and constraints linked to mesh-related issues. It allows for seamless numerical simulations from a virgin material to fully formed discrete cracks, within a non-local framework avoiding many numerical problems associated to mechanical softening. In contrast with other non-local methods, the non-local character of the TLS is geometrically limited to regions of interest, avoiding for example the issue of additional boundary conditions.

Taking advantage of these appealing features, we were able to setup numerical models of composite laminates, and perform simulations of transverse cracks development and interactions within this type of heterogeneous structures. In a first stage, we studied the influence of the two main algorithmic parameters introduced by the TLS approach: a characteristic length $l_{c}$ and a damage profile $d(\phi)$ used to enforce non-locality within the damage front region. It was observed that, if the characteristic length has a limited effect on results such as crack density, the damage profile shows a strong influence on results. Moreover, numerical experiments have shown that 
two specific damage profiles (namely a linear expression and an expression in arctan) led to the most physical results for this specific problem of multilayered materials. In addition, the arctan2 profile led to the appearance of a process zone ahead of the crack tip, in agreement with many experimental observations in organic matrix composites, and was thus used exclusively in the remaining numerical simulations. Ongoing work is aiming at a better and more systematic understanding of how the damage profile influences the development of damaged zones and cracks, beyond the conclusions obtained from this particular study.

With these optimized algorithmic parameters, it was shown that the TLS numerical model was able to reproduce crack interaction phenomena such as crack saturation in layered materials, showing good agreement with results from the literature, obtained from experimental measures or other computational methods. Several simulations were also performed to study transverse cracks development within different types of composite laminates $\left(\left[0^{\circ}, 90_{n}^{\circ}, 0^{\circ}\right]\right.$ and $\left[90_{n}^{\circ}, 0^{\circ}, 90_{n}^{\circ}\right]$ stacking sequences), demonstrating both qualitative agreement (e.g. crack placement) and quantitative agreement (crack densities) with available data from the literature.

Simulations presented in this paper required between 4 hours (for the simpler ones, with preexisting cracks), up to about 48 hours (for the simulations starting with a virgin material and finishing with a fully crack-saturated weak layer), on a standard single processor desktop computer. Note that there is a lot of room left for optimization of the mathematical solvers, and of the code itself, and that these computation times have already significantly decreased since the first simulations were run.

These results tend to show that the TLS could constitute an interesting approach to study fracture scenarios and crack patterns in heterogeneous materials such as composites. In some of the simulations shown above, one can observe propagation along interfaces once transverse cracks saturation has been reached. As noted before, this qualitatively looks like the early stages of a delamination process. Yet, the proper way to model interfaces between materials (either with a jump of properties or with a smoother gradient), both from the numerical and the physical points of view remains an open issue, currently under investigation.

Finally, it is well established that free boundaries effects are absolutely critical in failure processes for composite laminates. A reliable numerical analysis of fracture scenarios in laminates thus requires to account for three-dimensional models, and the bi-dimensional models used here are limited to describe generic effects, such as crack saturation. Implementation of a threedimensional version of the TLS algorithms has recently been completed, and future work will focus on such simulations of complex failure scenarios in composites and other heterogeneous materials.

\section{Acknowledgements}

The authors would like to thank Nicolas Moës (for the many discussions) and Kevin Moreau (for sharing his graphical skills).

\section{References}

Andersons, J., Joffe, R., Sparnins, E., 2008. Statistical model of the transverse ply cracking in cross-ply laminates by strength and fracture toughness based failure criteria. Engineering Fracture Mechanics 75 (9), 2651-2665. 
Bai, T., Pollard, D. D., 1999. Spacing of fractures in a multilayer at fracture saturation. International Journal of Fracture 100, L23-L28.

Bai, T., Pollard, D. D., Gao, H., 2000. Explanation for fracture spacing in layered materials. Nature 403, 753-756.

Baldelli, A. A. L., Bourdin, B., Marigo, J.-J., Maurini, C., 2011. Étude de la multifissuration et délamination par l'approche variationnelle à la mécanique de la fracture. In: 10e colloque national en calcul des structures. Giens, France, p. 8 p.

URL https://hal.archives-ouvertes.fr/hal-00592809

Bernard, P.-E., Moës, N., Chevaugeon, N., 2012. Damage growth modeling using the thick level set (tls) approach: efficient and accurate discretization for quasi-static loadings. Computer Methods in Applied Mechanics and Engineering 233-236, 11-27.

Berthelot, J.-M., Le Corre, J.-F., 2000. Statistical analysis of the progression of transverse cracking and delamination in cross-ply laminates. Composites Science and Technology 60 (14), 2659-2669.

Berthelot, J.-M., Leblond, P., Mahi, A. E., Le Corre, J.-F., 1996. Transverse cracking of cross-ply laminates: Part 1. analysis. Composites Part A: Applied Science and Manufacturing 27 (10), 989-1001.

Dvorak, G. L., Laws, N., 1987. Analysis of progressive matrix cracking in composites laminates. Journal of Composites Materials 21 (4), 309-329.

Garret, K., Bailey, J., 1977. Multiple transverse cracking in $90^{\circ}$ cross-ply laminates of a glass fibre-reinforced polyester. Journal of Materials Science 12, 157-168.

Germain, P., Nguyen, Q. S., Suquet, P., 1983. Continuum thermodynamics. Journal of Applied Mechanics 50, 10101020.

Halphen, B., Nguyen, Q. S., 1975. Sur les matériaux standard généralisés. J. Mécanique 14 (1), 39-63.

Hashin, Z., 1996. Finite thermoelastic fracture criterion with application to laminate cracking analysis. Journal of the Mechanics and Physics of Solids 44 (7), 1129-1145.

Highsmith, A. L., Reifsnider, K. L., 1982. Stiffness-reduction mechanisms in composite laminates. In: Reifsnider, K. L. (Ed.), Damage in Composite Materials. ASTM STP 775, pp. 103-177.

Hong, A., Li, Y., Bazant, P., 1997. Theory of crack spacing in concrete pavements. Journal of Engineering Mechanics $123,267-275$.

Ladevèze, P., Le Dantec, E., 1992. Damage modelling of the elementary ply for laminated composites. Composites Science and Technology 43 (3), 257-267.

Ladevèze, P., Lubineau, G., 2001. On a damage mesomodel for laminates: micro-meso relationships, possibilities and limits. Composites Science and Technology 61 (15), 2149-2158.

Ladevèze, P., Lubineau, G., Marsal, D., 2006. Towards a bridge between the micro- and mesomechanics of delamination for laminated composites. Composites Science and Technology 66 (6), 698-712.

Lemaitre, J., Chaboche, J. L., Benallal, A., Desmorat, R., 2009. Mécanique des matériaux solides, 3rd Edition. Dunod.

Manders, P. W., Chou, T. W., Jones, F. R., Rock, J. W., 1983. Statistical analysis of multiple fracture in $0^{\circ} / 90^{\circ} / 0^{\circ}$ glass fibre/epoxy resin laminates. Journal of Materials Science 18 (10), 2876-2889.

Moës, N., Stolz, C., Bernard, P., Chevaugeon, N., 2011. A level set based model for damage growth: The thick level set approach. International Journal for Numerical Methods in Engineering 86 (3), 358-380.

Nairn, J. A., 2000. Exact and variational theorems for fracture mechanics of composites with residual stresses, traction-loaded cracks, and imperfect interfaces. International Journal of Fracture 105 (3), 243-271.

Okabe, T., Nishikawa, M., Takeda, N., 2008. Numerical modeling of progressive damage in fiber reinforced plastic cross-ply laminates. Composites Science and Technology 68 (10-11), 2282-2289.

Okabe, T., Sekine, H., Noda, J., Nishikawa, M., Takeda, N., 2004. Characterization of tensile damage and strength in GFRP cross-ply laminates. Materials Science and Engineering A 383 (2), 381-389.

Parvizi, A., Garrett, K., Bailey, J., 1978. Constrained cracking in glass fiber-reinforced epoxy cross-ply laminates. Journal of Materials Science 13 (3), 195-201.

Peerlings, R., de Borst, R., Brekelmans, W., de Vree, J., 1996. Gradient enhanced damage for quasi-brittle materials. International Journal for Numerical Methods in Engineering 39 (19), 3391-3403.

Pijaudier-Cabot, G., Bažant, Z., 1987. Nonlocal damage theory. Journal of Engineering Mechanics 113 (10), 15121533.

Price, N. J., 1966. Fault and Joint Development in Brittle and Semi-Brittle Rocks. Oxford, Pergamon Press. 
Rebière, J.-L., Gamby, D., 2004. A criterion for modelling initiation and propagation of matrix cracking and delamination in cross-ply laminates. Composites Science and Technology 64 (13-14), 2239-2250.

Thouless, M. D., Olsson, E., A., G., 1992. Cracking of brittle films on elastic substrates. Acta Metallurgica Materialia 40, 1287-1292.

Varna, J., Joffe, R., Akshantala, N. V., Talreja, R., 1999. Damage in composite laminates with off-axis plies. Composites Science and Technology 59 (14), 2139-2147.

Wang, A. S. D., 1984. Fracture mechanics of sublaminate cracks in composite materials. Journal of Composites, Technology and Research 6 (2), 45-62.

Wu, H., Pollard, D. D., 1995. An experimental study of the relationship between joint spacing and layer thickness. Journal of Structural Geology 17 (6), 887-905. 